\title{
Abnormal male meiosis explains pollen sterility in the polyploid medicinal plant Pinellia ternata (Araceae)
}

\author{
Y. Liu', R.-K. Hui², R.-N. Deng', J.-J. Wang', M. Wang' and Z.-Y. Li ${ }^{1}$ \\ ${ }^{1}$ Institute of Medicinal Plants, College of Plant Science and Technology, \\ Huazhong Agricultural University, Wuhan, P.R. China \\ ${ }^{2}$ Crop Institute, Hunan Academy of Agricultural Sciences, Hunan, P.R. China \\ Corresponding author: Z.-Y. Li \\ E-mail: lizaiyun@mail.hzau.edu.cn
}

Genet. Mol. Res. 11 (1): 112-120 (2012)

Received May 11, 2011

Accepted October 20, 2011

Published January 17, 2012

DOI http://dx.doi.org/10.4238/2012.January.17.1

\begin{abstract}
Pinellia ternata is an important traditional Chinese medicinal plant. Its different populations in China have various ploidy levels, based on $x=13$, as well as extensive aneuploid series. The microsporogenesis process was observed in specimens from three populations from three regions of Hubei Province; they were characterized by normal and abnormal meiotic divisions in pollen mother cells (PMCs) at all stages simultaneously. Meiotic abnormalities including univalents/multivalents, chromosomal laggards/bridges and micronuclei appeared in about $50 \%$ of the PMCs, together with abnormal cytokinesis. Chromatin/chromosome transfer between meiocytes occurred only during the first division, at low frequency; this might contribute to these meiotic abnormalities. Although the remaining 50\% of the PMCs presented normal cytological behavior, pollen fertility was only about $2 \%$. These results provide cytological explanations for its low seed-set and the general use of asexual reproduction through tubers
\end{abstract}


and bulbils; it also explains the wide variations in chromosome number.

Key words: Pinellia ternata; Cytomixis; Microsporogenesis; Meiosis; Polyploidy

\section{INTRODUCTION}

Pinellia Tenore is a small eastern Asian genus of the family Araceae (Mayo et al., 1997) and includes only seven perennial herbaceous species. Pinellia ternata is an important traditional Chinese medicinal plant and was recorded in Chinese herb classics more than 2000 years ago $(\mathrm{Li}, 1979)$. It has been used for the treatment of viper bites, lumbago, allergic reaction, and externally for the treatment of traumatic injury, abscesses, neck lymphosarcoma, breast mastitis, and uterine cancer (Li, 1979; Luo and Zhou, 1979). Its wild forms are found in all but a few provinces, such as Tibet and Qinghai.

P. ternata has been found to present several ploidy levels with two basic chromosome numbers $(\mathrm{x}=9$, 14) (Huttoleston, 1942; Gu and Xu, 1991; Li, 1995; Li et al., 1997). Some populations were reported to be aneuploids (Ito, 1942; Malvesin-Fabre, 1972; Marchant, 1972). However, the chromosome investigations of ten populations from nine provinces of China showed that they were euploids $(6 x-9 x)$ with $\mathrm{x}=13$ (Yi et al., 2005). Another study on 27 populations from 16 provinces in China revealed that $P$. ternata was a polyploid complex $(7 x-10 x)$ still with $\mathrm{x}=13$, while a minority of this species were aneuploids $(2 \mathrm{n}=92,103$, 105, 115) (Chen et al., 2006). Another population in China had 2n $=90$ (Wang et al., 2000). So the conclusion was that genetic differentiation and the phenomenon of ploidy miscellany commonly existed in the species in China.

All the species of Pinellia can propagate by tubers or rhizomes and some by bulbils. P. ternata mainly shows asexual reproduction through tubers and bulbils, because its sexual reproduction degenerates by expressing low seed-set and poor seed germination. This reproduction characteristic is probably related to its diverse polyploidy levels as well as the aneuploids. The meiotic abnormalities including univalents/multivalents, chromosomal laggards and bridges contributed to the very low fertility of pollen grains in the population with $2 \mathrm{n}=90$ (Wang et al., 2000).

Cytomixis, the chromatin/chromosome transfer between the proximate meiocytes through cytoplasmic channels or intercellular bridges, has been reported during microsporogenesis in a wide range of flowering plants (Heslop-Harrison, 1966; Wu et al., 2003; Datta et al., 2005; Sheidai and Fadaei, 2005; Ghaffari, 2006; Lattoo et al., 2006; Singhal and Kumar, 2008a,b; Maity and Datta, 2009). The occurrence of cytomixis is found to be more prevalent in genetically, physiologically and biochemically unbalanced plants such as apomicts and aneuploids (Haroun, 1995; Nirmala and Rao, 1996), and also more prevalent among polyploids (Semyarkhina and Kuptsou, 1974; Singhal et al., 2007). Cytomixis is directly responsible for abnormal meiotic behavior, pollen grains of different sizes and pollen sterility (Singhal and Kumar, 2008b). Cytomixis could be considered a process of evolutionary significance in plant populations (Falistocco et al., 1995; Ghanima and Talaat, 2003; Malallah and Attia, 2003; Boldrini et al., 2006; Li et al., 2009), because it results in changes in gametic chromosome numbers through migration of chromosomes between adjacent meiocytes, although there is still some controversy about its role in evolution. 
In the present study, three P. ternata populations collected in the Hubei Province of China were found to have quite different chromosome numbers $(2 n=26-114)$. During the process of microsporogenesis, chromosomes were paired as bivalents predominantly with some multivalents at diakinesis. But meiotic aberrants prevailed at later stages, including cytomixis, chromosome laggards, asymmetric segregation, and polyads, which resulted in very low fertility for males. These results provide some new insights into the reproduction characteristics of this complex species with chromosome variations.

\section{MATERIAL AND METHODS}

Tuber samples of wild growing P. ternata were collected from three regions in the Hubei Province of China: Qianjiang, Jinzhou and Xingshan. One sample from each region was obtained and then planted in the medicinal plant garden on the campus of our university for study.

Chromosome numbers were determined in root-tip cells and at least 50 cells were observed for each sample. Root tips measuring about $0.5 \mathrm{~cm}$ were pretreated in $2 \mathrm{mM} 8$-hydroxyquinoline for $4 \mathrm{~h}$ at room temperature and fixed in 3 ethanol:1 acetic acid for at least $24 \mathrm{~h}$, transferred to $70 \%$ ethanol and stored at $4{ }^{\circ} \mathrm{C}$ until use. The spikelets at the ideal stages for meiotic studies and for pollen development were fixed directly and then stored at $4^{\circ} \mathrm{C}$ for use. Chromosome preparations followed the method of Li et al. (1995). Pollen viability was estimated as the percentage of pollen grains stained with $1 \%$ aceto-carmine. Preparations were checked and the photomicrographs taken with a microscope (Nikon Eclipse 80i, Japan) with a CCD camera.

\section{RESULTS}

\section{Phenotype and chromosome numbers}

The individual plants from each region showed variations in leaf morphology, but the phenotypes were similar in the plants from the three regions. The different chromosome numbers with $2 n=80-114$ were also presented by the plants from each region (Figure 1), as reported previously. The leaf morphology was not related with chromosome number.

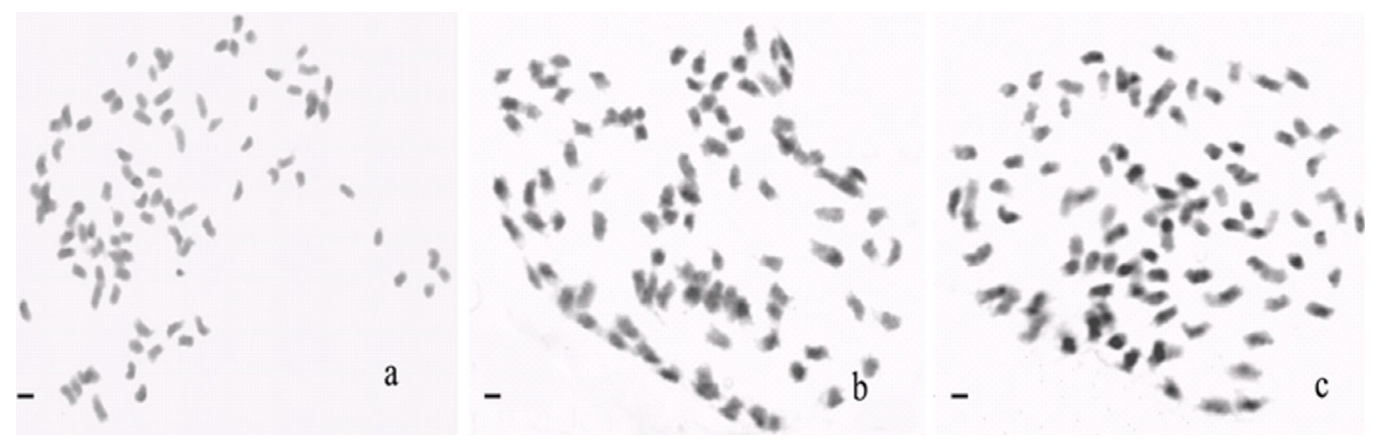

Figure 1. Different chromosome numbers in root-tip cells of Pinellia ternata. a. 2 n $=88$. b. $2 n=96$. c. $2 n=102$. Bar $=2 \mu \mathrm{m}$. 
During mitotic divisions of root cells, chromosomal laggards and bridges appeared at metaphase, anaphase and telophase in about $10 \%$ of cells, which might produce the cells with different chromosome numbers within each plant.

\section{Meiosis and microsporogenesis}

The processes of microsporogenesis in all plants from the three regions observed were characterized by normal and abnormal meiotic divisions in pollen mother cells (PMCs) at all stages simultaneously. The percentages of PMCs with abnormal divisions varied from $41.92 \%$ at prophase II to $88.37 \%$ at diakinesis, totaling about $50 \%$ (Table 1 ). But the pollen stainability was quite low, only about $2 \%$ (Figure 21).

\begin{tabular}{|c|c|c|c|c|}
\hline Phases & Total number of cells & $\begin{array}{c}\text { Number and percentage } \\
\text { of abnormal cells }\end{array}$ & Abnormalities & Number of cells \\
\hline Diakinesis & 516 & $456(88.37)$ & $\begin{array}{l}\text { Multiple chromosome associations } \\
\text { Chromosome structural variation } \\
\text { Cytomixis }\end{array}$ & $\begin{array}{r}387 \\
63 \\
6\end{array}$ \\
\hline Metaphase I & 586 & $413(70.48)$ & $\begin{array}{l}\text { Precocious migration } \\
\text { Laggards } \\
\text { Abnormal cytokinesis }\end{array}$ & $\begin{array}{r}272 \\
128 \\
13 \\
\end{array}$ \\
\hline Anaphase I & 292 & $145(49.66)$ & $\begin{array}{l}\text { Laggards } \\
\text { Bridges } \\
\text { Abnormal cytokinesis }\end{array}$ & $\begin{array}{l}84 \\
33 \\
28 \\
\end{array}$ \\
\hline Telophase I & 219 & $103(47.03)$ & $\begin{array}{l}\text { Micronuclei } \\
\text { Abnormal cytokinesis }\end{array}$ & $\begin{array}{l}82 \\
21\end{array}$ \\
\hline Prophase II & 167 & $70(41.92)$ & Micronuclei & 70 \\
\hline Metaphase II & 572 & $240(41.96)$ & $\begin{array}{l}\text { Laggards } \\
\text { Abnormal cytokinesis }\end{array}$ & $\begin{array}{r}176 \\
64\end{array}$ \\
\hline Anaphase II & 328 & $203(61.89)$ & $\begin{array}{l}\text { Laggards } \\
\text { Bridges } \\
\text { Abnormal cytokinesis }\end{array}$ & $\begin{array}{l}60 \\
47 \\
96\end{array}$ \\
\hline Telophase II & 260 & $171(65.77)$ & $\begin{array}{l}\text { Micronuclei } \\
\text { Abnormal cytokinesis }\end{array}$ & $\begin{array}{l}86 \\
85\end{array}$ \\
\hline Microspores & 375 & $182(48.53)$ & $\begin{array}{l}\text { Tetrad with micronuclei } \\
\text { Polyad }\end{array}$ & $\begin{array}{r}79 \\
103\end{array}$ \\
\hline
\end{tabular}

*The data for three populations were pooled because their behaviors were similar.

In those PMCs showing normal divisions, the chromosomes, although high in number, paired at diakinesis predominantly as bivalents, congregated in the equatorial plane at metaphase I (MI), moved to the two poles during anaphase II (AII) and were finally included in the two daughter nuclei at telophase II (TII) (Figure 2a,j). It was usually difficult to determine the exact pairing configurations for the high number of bivalents and some multivalents. After the karyokinesis, cytokinesis occurred during the first division and two daughter cells were formed (Figure 2e). During the second division (Figure 2f,j), the chromosomes became diffuse at prophase II, arranged themselves properly on the equatorial plane at MII, and chromatids moved to the opposite poles during AII and nuclei reformed around the chromosomes at the poles at TII. The spindle fibers were visible in PMCs at AI and AII. Finally, the tetrads were formed. During the development of male gametophytes/ 


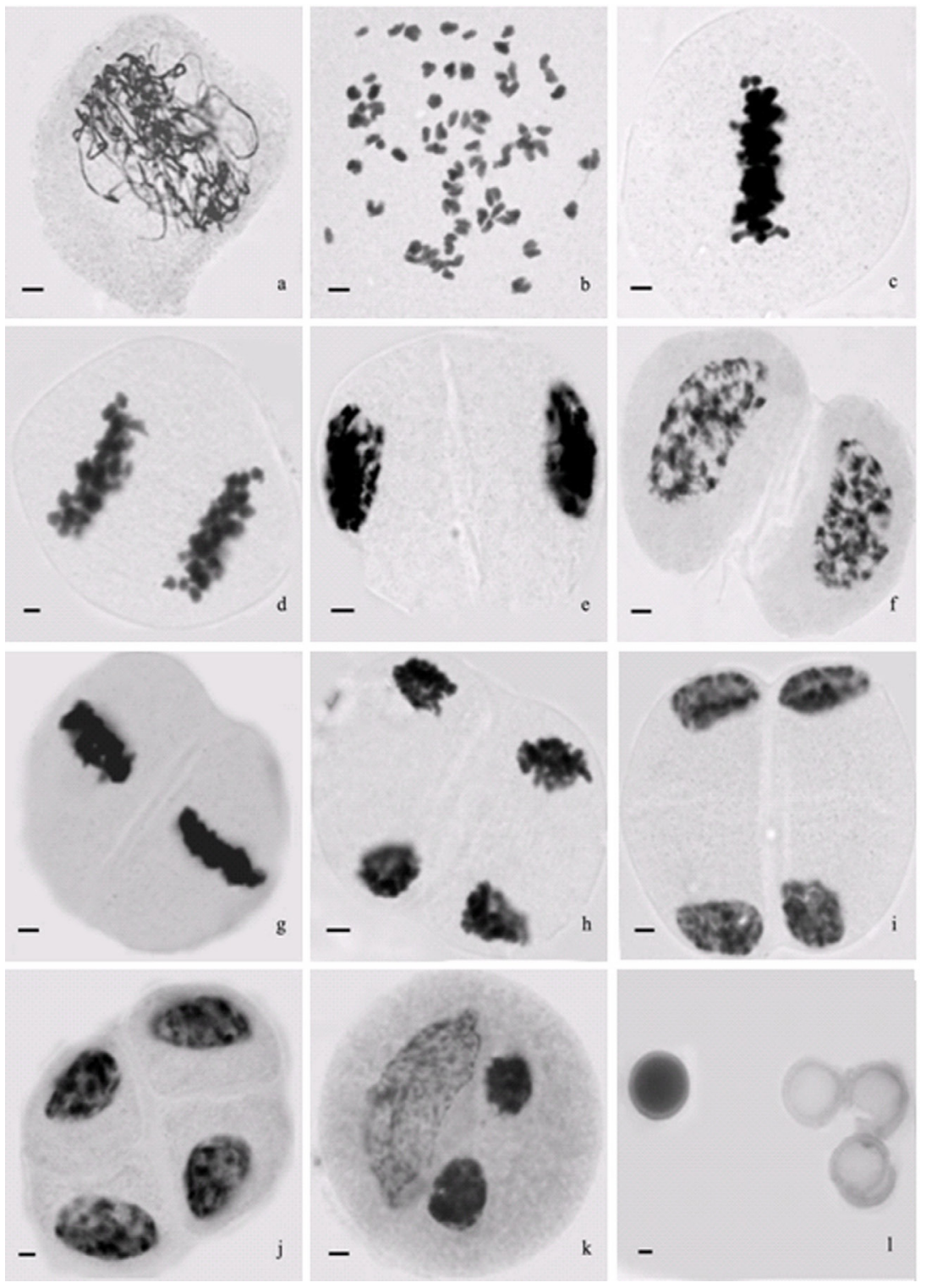

Figure 2. Normal meiotic divisions in PMCs of Pinellia ternata. a. Pachytene. b. Diakinesis with about 50 bivalents. c. Metaphase I. d. Anaphase I. e. Telophase I. f. Prophase II. g. Metaphase II. h. Anaphase II. i. Telophase II. j. Tetrad. k. Trinucleate pollen. I. Stainable and unstainable pollen grains. Bar $=2 \mu \mathrm{m}$.

pollen grains, the uninucleate pollen had a large nucleus and condensed chromatin, the binucleate pollen had one decondensed vegetative nucleus and one condensed generative nucleus, while the trinucleate pollen had one large but decondensed vegetative nucleus and two small condensed generative nuclei (Figure 2k). 
In those PMCs with abnormal chromosomal behaviors, univalents and multivalents including quadri-/hexavalents appeared at diakinesis with certain frequency, laggards and chromosomal bridges prevailed at MI/MII, AI/II, and TI/II (Table 1, Figure 3). Micronuclei were produced at TI/TII; tetrads with micronuclei or polyads of different sizes prevailed and accounted for nearly one half of meiotic products. Transfer of chromatin between PMCs (cytomixis) with low frequency was only observed at diakinesis or in earlier stages (Table 1, Figure 3a,b).

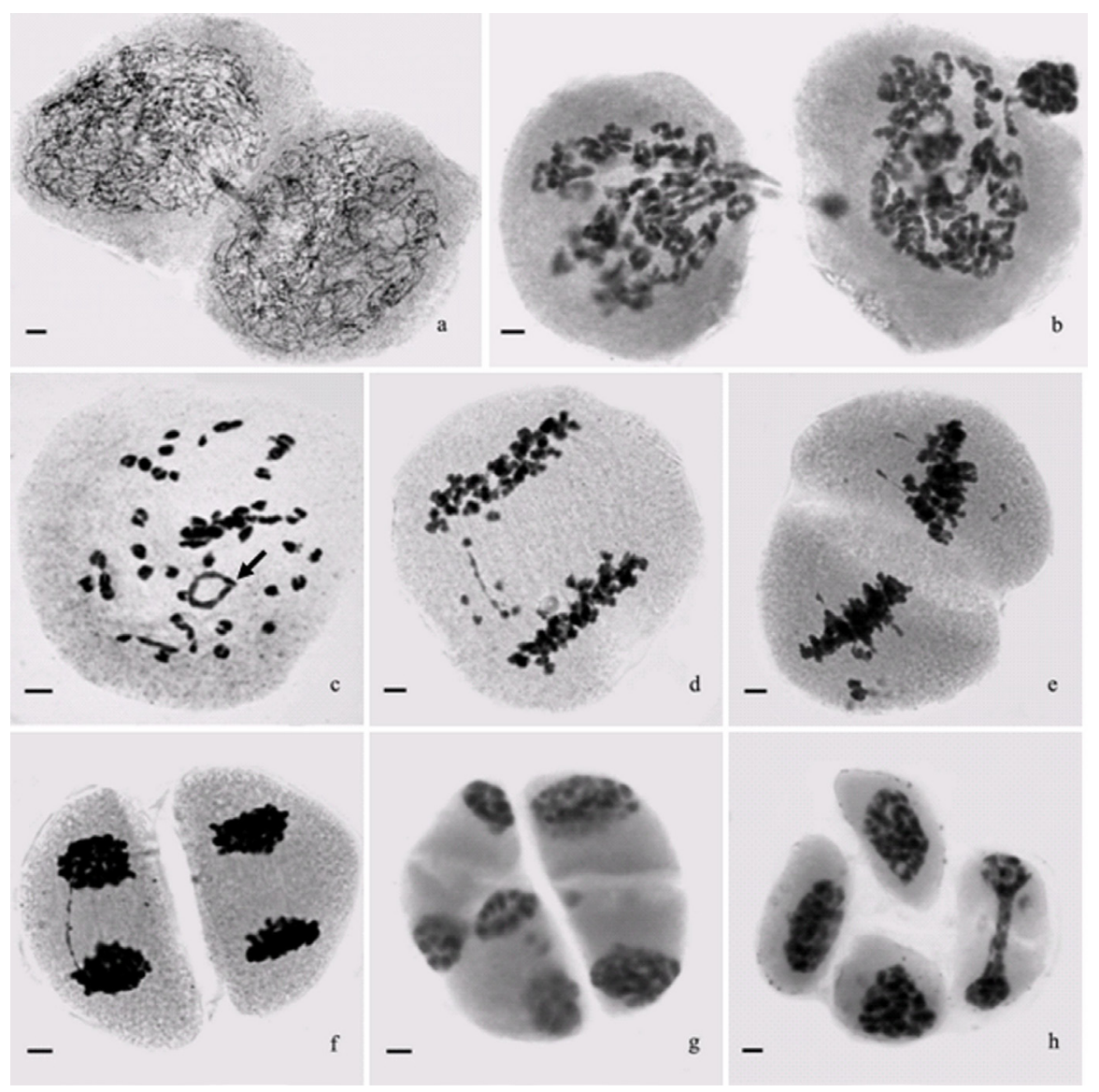

Figure 3. Meiotic abnormalities in Pinellia ternata. a. b. Transfer of chromatin between PMCs at two stages of prophase I. c. One PMC at diakinesis with some multivalents (arrow). d.-f. PMCs with laggards and bridges at AI (d), MII (e) and TII (f). g. h. Polyads with micronuclei and bridges. Bar $=2 \mu \mathrm{m}$.

Another prominent phenomenon was abnormal karyokinesis and cytokinesis in PMCs from MI to TII (Table 1, Figure 4), which resulted in a quite unequal distribution of chromosomes/chromatin in daughter cells, even in the formation of anucleated cells (Figure 5). The anucleated cells were produced during the first and second divisions, and seemingly cytokinesis occurred prior to karyokinesis in some cases (Figure 5d,e). Of course, the laggards, bridges and micronuclei also occurred in these PMCs (Figures 4, 5). 


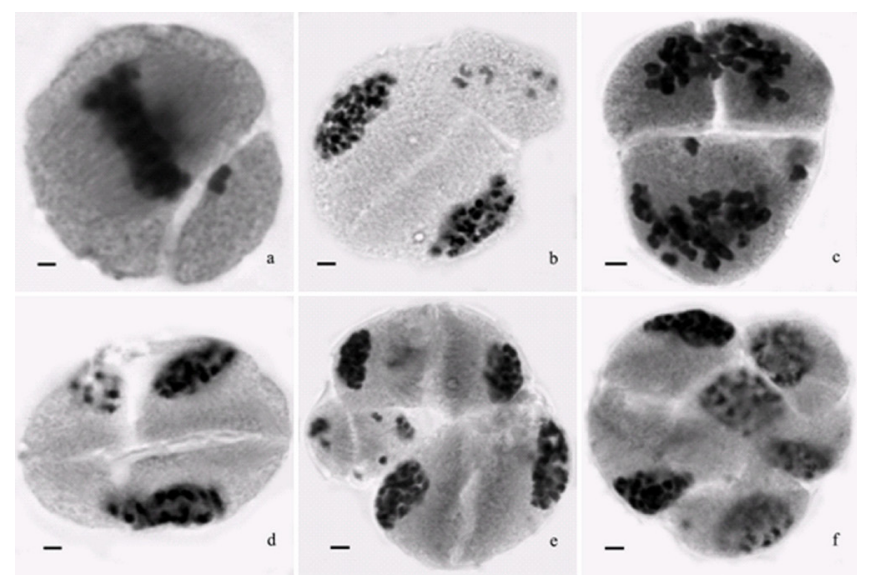

Figure 4. Unequal distribution of chromosomes/chromatin into daughter cells during meiosis in Pinellia ternata. a. One PMC at MII with only two chromosomes in one daughter cell (right). b. One PMC at AI/TI, one daughter cell containing a few chromosomes (top right). c. One PMC at AI, one daughter cell from first division underwent unequal division again and produced one nucleus with one chromosome and the other with many chromosomes (bottom). d. One tetrad produced by one PMC, one daughter cell from first division underwent unequal division again and produced two nuclei with different contents of chromatin (left). e. Three daughter cells produced by one PMC underwent second division and gave rise to six nuclei with different amounts of chromatin. Some lagging chromosomes appeared in the two nuclei (middle left). f. Polyad from one PMC with different sizes of nuclei. Bar $=2 \mu \mathrm{m}$.

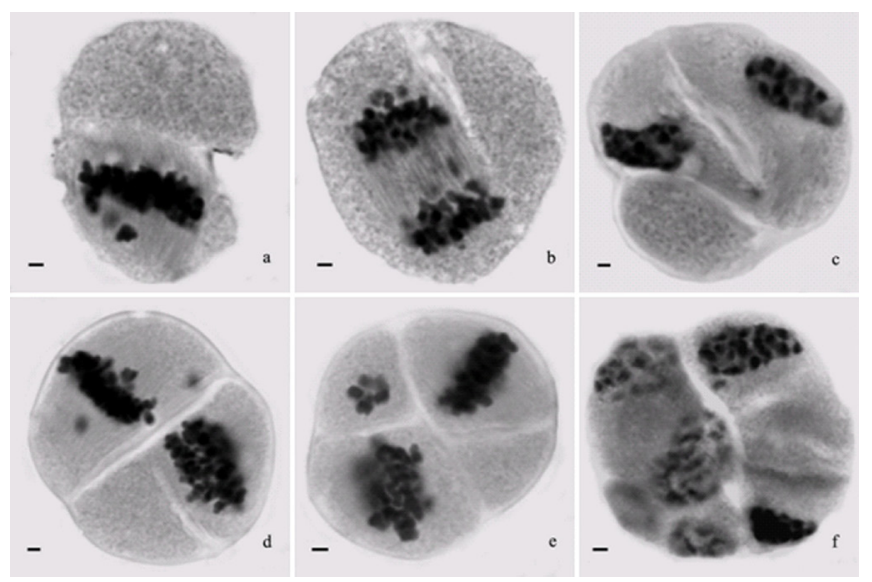

Figure 5. Meiotic divisions with the formation of anucleated daughter cells. a. One PMC at MII, in which one daughter cell was anucleated (top) and the other at metaphase (bottom) had spindle visible and some lagging chromosomes. b. One PMC at AII. The daughter cell (right) was anucleated and the other (left) at anaphase had spindle fibers visible and also some laggards. c. One PMC at TII. The nucleated daughter cell (top) produced two nuclei, while the anucleated daughter cell remained undivided (bottom). d. One PMC at MII. The cytokinesis occurred prior to karyokinesis in one daughter cell (below) and resulted in the formation of the anucleated cell and the nucleated cell with chromosomes being divided. Then, the nucleated cell contained the duplicated chromosomes. e. One PMC showing prior cytokinesis and unequal distribution of chromosomes during second division. The two cells (left) were likely formed through unequal distribution of chromosomes in one daughter cell from the first division. The other two (right) were produced by prior cytokinesis in another daughter cell from the first division. f. Polyads with different amounts of chromatin and anucleated cells. Bar $=2 \mu \mathrm{m}$. 


\section{DISCUSSION}

In the present study, male meiosis and microsporogenesis of $P$. ternata were observed in three populations collected in the Hubei Province of China. The results showed that meiotic abnormalities, including univalents/multivalents, chromosomal laggards/bridges and micronuclei, appeared in about $50 \%$ of PMCs, together with abnormal cytokinesis (Table 1, Figures 3,5 ). These abnormalities resulted in the production of the meiotic products with different amounts of the genetic elements and subsequently sterile pollen. Although the remaining $50 \%$ of PMCs presented normal cytological behavior, the pollen fertility was quite low, only about $2 \%$, which suggested that the male gametes from these PMCs contained unbalanced chromosome complements or that pollen development was disturbed for some unknown reason. The poor male fertility caused by the meiotic abnormalities also explained its low seed-set and poor seed germination and asexual reproduction through tubers and bulbils.

Cytomixis was observed at certain meiotic phases, or in all stages (de Souza and Pagliarini, 1997; Pierozzi and Benatti, 1998; Malallah and Attia, 2003), more frequently in the first division (Bellucci et al., 2003; Lattoo et al., 2006). The transfer of chromatin material during microsporogenesis was considered to cause various meiosis abnormalities, reduced pollen viability and heterogeneous-sized pollen grains (Singhal and Kumar, 2008a). Here, the occurrence of cytomixis in Pinellia only during first division with low frequency might also contribute to some of the meiotic abnormalities observed, such as univalents, chromosome laggards and bridges, micronuclei, low pollen stainability, and poor seed-set, because the transfer of different amounts of chromatin resulted in the unbalanced complements of the PMCs involved.

A compilation of the chromosome numbers reported for the different populations of $P$. ternata in China supports its variable polyploidy levels based on $\mathrm{x}=13$, as well as extensive aneuploidy series ( $\mathrm{Li}$ et al., 1997; Chen et al., 2006), while assumptions about basic numbers different from $\mathrm{x}=13$ (i.e., $\mathrm{x}=7$, 9, see Li et al., 1997) should be made with great caution and counts of higher ploidy levels deviating from $\mathrm{x}=13$ are apparently due to aneuploid reduction (Zhu et al., 2007). The aneuploidy series probably originated from meiotic abnormalities, particularly cytomixis, because it has been shown to be a potential means for conserving the genetic heterozygosity of gametes (Veilleux, 1985) and an additional means of creating aneuploids and polyploids (Sarvella, 1958; Falistocco et al., 1995). The low pollen viability of $P$. ternata is compensated by its perennial behavior, by asexual reproduction through tubers and bulbils.

\section{REFERENCES}

Bellucci M, Roscini C and Mariani A (2003). Cytomixis in pollen mother cells of Medicago sativa L. J. Hered. 94 : $512-$ 516.

Boldrini KR, Pagliarini MS and Do Valle CB (2006). Cell fusion and cytomixis during microsporogenesis in Brachiaria humidicola (Poaceae). South Afr. J. Bot. 72: 478-481.

Chen CB, Ma XJ, Chen L, Xue M, et al. (2006). Studies on cytogeography of Pinellia ternata poliploid complex. Zhongguo Zhong. Yao Za Zhi. 31: 1405-1408.

Datta AK, Mukherjee M and Iqbal M (2005). Persistent cytomixis in Occimum basilicum L. (Lamiaceae) and Withania somnifera (L.) Dun (Solanaceae). Cytologia 70: 309-313.

de Souza A and Pagliarini M (1997). Cytomixis in Brassica napus var. oleifera and Brassica campestris var. oleifera (Brassicaceae). Cytologia 62: 25-29.

Falistocco E, Tosti N and Falcinelli M (1995). Cytomixis in pollen mother cells of diploid Dactylis, one of the origins of 2n gametes. J. Hered. 86: 448-453.

Ghaffari SM (2006). Occurrence of diploid and polyploidy microspores in Sorghum bicolor (Poaceae) is the result of 
cytomixis. Afr. J. Biotechnol. 5: 1450-1453.

Ghanima AM and Talaat AA (2003). Cytomixis and its possible evolutionary role in a Kuwaiti population of Diplotaxis harra (Brassicaceae). Bot. J. Linn. Soc. 143: 169-175.

Gu DX and Xu PS (1991). A comparison of the variation patterns of populations between two species of Pinellia from Nanjing. Acta Phytotaxon. Sin. 29: 423-430.

Haroun SA (1995). Cytomixis in pollen mother cells of Polygonum tomentosum Schrank. Cytologia 60: 257-260.

Heslop-Harrison J (1966). Cytoplasmic connexions between angiosperm meiocytes. Ann. Bot. 30: 221-222.

Huttoleston DG (1942). Lysichiton version versus Lyschichitum. Bull. Torrey Bot. Club 108: 479-481.

Ito T (1942). Chromosome und Sexualität der Araceae. I. Somatische hromosomenzahlen einiger Arten. Cytologia 12: 313-325.

Lattoo SK, Khan S, Bamotra S and Dhar AK (2006). Cytomixis impairs meiosis and influences reproductive success in Chlorophytum comosum (Thunb) Jacq. - an additional strategy and possible implications. J. Biosci. 31: 629-637.

Li H (1979). The 'tian-nan-xing', 'hu-zhang' and 'ban-xia' in Chinese herbalogies. Acta Bot. Yunnanica 2: 13-26.

Li L (1995). A Systematic Study of the Genus Pinellia tenore (Araceae) in China. Proc. VI International, Aroid Conference, Editorial Department Acta Botanic Yunnanica, Kunming, 44.

Li MW, Gu DX and Liu YL (1997). Several variation patterns and their evolution of Pinellia (Araceae). J. Wuhan Bot. Res. 15: 317-322.

Li XF, Song ZQ, Feng DS and Wang HG (2009). Cytomixis in Thinopyrum intermedium, Thinopyrum ponticum and its hybrids with wheat. Cereal Res. Commun. 37: 353-361.

Li Z, Liu HL and Luo P (1995). Production and cytogenetics of intergeneric hybrids between Brassica napus and Orychophragmus violaceus. Theor. Appl. Genet. 91: 131-136.

Luo HS and Zhou DH (1979). Brief introduction of Chinese medicine commonly used as anti-tumor. J. New. Chin. Medicine 4: 53-54.

Maity S and Datta AK (2009). Meiosis in nine species of Jute (Corchorus). Indian J. Sci. Tech. 2: 27-29.

Malallah GA and Attia TA (2003). Cytomixis and its possible evolutionary role in a Kuwaiti population of Diplotaxis harra (Brassicaceae). Bot. J. Linn. Soc. 143: 169-175.

Malvesin-Fabre G (1972). Contribution à la Caryologie des Aracées. E. Drouillard, Bordeaux.

Marchant CJ (1972). Chromosome variation in Araceae: IV* Areae. Kew Bull. 26: 395-404.

Mayo SJ, Bogner J and Boyce PC (1997). The genera of Araceae. Kew: Royal Botanic Gardens 280-283.

Nirmala A and Rao PN (1996). Genesis of chromosome numerical mosaicism in higher plants. Nucleus 39: 151-175.

Pierozzi NI and Benatti R (1998). Cytological analysis in the microsporogenesis of ramie, Boehmeria nivea Gaud. (Urticaceae) and the effect of colchicine on the chiasma frequency. Cytologia 63: 213-221.

Sarvella P (1958). Cytomixis and loss of chromosomes in meiotic and somatic cells of Gossypium. Cytologia 33: 14-24.

Semyarkhina SY and Kuptsou MS (1974). Cytomixis in various forms of sugarbeet. Vests. I. AN BSSE. Ser. Biyal. 4: 43-47.

Sheidai M and Fadaei F (2005). Cytogenetic studies in some species of Bromus L., section Genea Dum. J. Genet 84: 189-194.

Singhal VK and Kumar P (2008a). Impact of cytomixis on meiosis, pollen viability and pollen size in wild populations of Himalayan poppy (Meconopsis aculeata Royle). J. Biosci. 33: 371-380.

Singhal VK and Kumar P (2008b). Cytomixis during microsporogenesis in the diploid and tetraploid cytotypes of Withania somnifera (L.) Dunal, 1852 (Solanaceae). Comp. Cytogenet. 2: 85-92.

Singhal VK, Gill BS and Dhaliwal RS (2007). Status of chromosomal diversity in the hardwood tree species of Punjab State. J. Cytol. Genet. 8: 67-83.

Veilleux R (1985). Diploid and polyploid gametes in crop plants: mechanism of formation and utilization in plant breeding. Plant Breed. Rev. 3: 253-288.

Wang ZX, Peng ZS and He YK (2000). Genetic analysis of male gamete abortion in Pinellia ternata. Acta Agron. Sin. 26: 83-86.

Wu W, Zheng YL, Yang RW and Chen L (2003). Variation of the chromosome number and cytomixis of Houttuynia cordata from China. J. Syst. Evol. 41: 245-257.

Yi TS, Li H and Li DZ (2005). Chromosome variation in the genus Pinellia (Araceae) in China and Japan. Bot. J. Linn. Soc. 147: 449-455.

Zhu GH, Li H and Li R (2007). A synopsis and a new species of the E Asian genus Pinellia (Araceae). Willdenowia 37: 503-522. 